\title{
Surgical management of traumatic wing in an Indian black kite (Milvas migrans)
}

\author{
F. Mridha ${ }^{1 *}$, C. K. Ghosh ${ }^{1}$ and S. Halder ${ }^{2}$ \\ ${ }^{1}$ Department of Veterinary Clinical Complex, West Bengal University of Animal and Fishery Sciences, \\ Kolkata-700 037, West Bengal, India; ${ }^{2}$ Department of Veterinary Surgery and Radiology, West \\ Bengal University of Animal and Fishery Sciences, Kolkata-700 037, West Bengal, India
}

\begin{abstract}
An injured Small Indian black kite (Milvas migrans) was rescued with injury on both wings due to attack of several dogs. The wing wounds were soiled and the bird was anaemic, dehydrated and off feed with non-weight-bearing lameness in the affected legs. Aseptic cleaning and proper pressure bandaging ceased the bleeding to stabilize the patient. Initially mouth to mouth slow respiration was instituted to maintain breathing. As the kite required large volume of fluid, subcutaneous $50 \mathrm{~mL}$ lukewarm dextrose $5 \%$ administration was done with 24G Butterfly catheter. Radiographic examination shows displacement of articular ends of cervical vertebrae and fracture of bony extension of left coracoid. Immobilization or fixation of cervical dislocation was done under general anesthesia by Coaptation splint with $\mathrm{X}$-ray film which was applied to prevent displacement or angulations of cervical vertebrae. Fractured shoulder extremity of left coracoid was managed by use of figure of 8 bandage with body wrap bandage using soft padding material. The bird was recovered with flying ability after 30 days by fluid management, antibiotic and anti-inflammatory therapy as well as proper nourishment with calcium supplementation.
\end{abstract}

Key words: Injured kite, Management, Rescue

Avian wildlife are prone to accidental injury and fractures (Howard and Redig, 1993). After an assessment to look for any lifethreatening injuries like active haemorrhage or fractures the patient should be administered appropriate analgesia and placed in a dark and quiet room. Butorphanol can be administered to most avian species at 0.5 to $4 \mathrm{mg} / \mathrm{kg}$ IV or IM; however, buprenorphine has been shown to have more efficacies in raptors (Ceulemans et al., 2014) and can be administered at 0.1 to $0.6 \mathrm{mg} / \mathrm{kg}$ IV or IM. Non-steroidal anti-inflammatory drug (NSAIDs) are not an ideal choice in patients on initial presentation, as shock and hypovolaemia with NSAID administration can lead to acute kidney injury. Administration of subcutaneous or oral fluids can help to treat shock (Mullineaux and Keeble, 2016). Patient evaluation, treatment with minimal stress and careful consideration should be taken to ensure a return to normal wild habitat.
An injured Small Indian black kite (Milvas migrans) was reported for rehabilitation by local people at Belgachia, Kolkata which was attacked by several dogs after accidental injury of both wings.

A previously prepared towel fitted, bottom taped cardboard box with a pencil diameter air holes and heating bag inside was used for transportation of the kite- like in a "nest" to avoid re-injuring and fly away of the bird. The kite was brought within an hour to the Veterinary Clinical Complex, W.B.U.A.F.S., Kolkata.

The wing wounds were freshened enough but heavily soiled. The size of the bird was normal and the bird was weak and looked anaemic due to heavy blood loss. The head was tilted and there was a period of eye closing. The movements were retarded, the eyes were sunken and pallor conjunctiva was noticed. The kite was totally dehydrated and off-feed. There was non-weight bearing lameness in the affected legs. The feathers 
were fluffed out but breathing was hard to detect. Physiological examination of the bird revealed a dull and depressed appearance but good body condition. The heartbeats were $150 / \mathrm{min}$ and the temperature was $40^{\circ} \mathrm{C}$. The weight of the bird was $650 \mathrm{gm}$. After cleaning and proper pressure bandaging on wings, it was found that bleeding was ceased, so the patient was taken to stabilize. Initially, mouth to mouth slow respiration was instituted to maintain breathing. As the bird was in respiratory distress and the environmental temperature was around $21^{\circ} \mathrm{C}$ it was placed on a heating pad covered with a towel. The head was tried to extend as much as possible without giving further pain and patent airway was tried to maintain after ruling out the possibility of airway obstruction for oxygenation. There were tachy wrinkled skin and sunken eyes which were evident of dehydration up to $10 \%$. As the kite required a large volume of fluid, subcutaneous fluid administration was done with $24 \mathrm{G}$ Butterfly catheter. Total $50 \mathrm{~mL}$ lukewarm dextrose 5\% was given to different loose skins avoiding wounds. After proper stabilization, the bird was sent for further examinations. The radiographic examination determined the area of neck involvement. The radiograph shows displacement of articular ends of cervical vertebrae and fracture of bony extension of the left coracoid. A diagnosis of several wounds, cervical dislocation and left shoulder injury with a state of shock was made based on history, physical examinations, haematological parameters, and radiographic findings.

For dressing of wounds, wings were clipped and micro tape was applied to restrict the movement for proper restraining. The nails were trimmed to prevent injury before dressing. The wounds were washed with hydrogen peroxide and normal saline for several times and afterwards with povidone iodine solution aseptically. Inj. amoxycillin and cloxacillin @ 5mg/kg was administered intramuscularly (Fowler, 2001). Suspension meloxicam @ $0.5 \mathrm{mg} / \mathrm{kg}$ PO BID was started as analgesic. Immobilization or fixation of cervical dislocation was done under general anaesthesia by ketamine $\mathrm{HCl} @ 40 \mathrm{mg} / \mathrm{kg}$ intramuscularly. Without clipping the feathers, applying sufficient cotton padding and after incorporating joints above and below the dislocated site Coaptation splint with X-ray film was applied to prevent displacement or angulation of cervical vertebrae and to prevent movement and pain as suggested by Kumar Amresh (2000). Fractured shoulder extremity of left coracoid was managed by use of figure of 8 bandage.

The bird was kept in a quiet place under quarantine in a towel padded cage. The bird was monitored after every two hours. As the kite was off fed subcutaneous $50 \mathrm{~mL}$ lukewarm dextrose $5 \%$ was given to different loose skin everyday. Injection amoxycillin and cloxacillin @ 5mg/kg twice daily intramuscularly for seven days with suspension meloxicam @ $0.5 \mathrm{mg} / \mathrm{kg}$ PO BID as NSAID for three days with a course of calcium liquid@0.5mL PO BID with water to assist healing and growing bones were given. It was advised to keep the bird in stall rest for thirty days. Fly repellent was applied in the quarantine place and in cage too. The bird was able to take chicken soup after five days with assisted feeding. After two weeks the bird was found to move its neck slowly. The bird was started to take feed after fifteen days and tiny chopped chicken and fishes were offered for feeding. The Coaptation splint with X-ray film was removed after twenty days. The bird was recovered completely with flying ability after 30 days after removal of figure of 8 bandage with body wrap bandage. The injured kite with wing wounds and cervical dislocation was thus treated successfully.

The management and treatment of wild avian patients must be approached in a different way than that of companion avian species. The aim is a return to free to the wild with as little rehabilitation time as possible. Pre rescue management was approached from behind of the injured kite quietly and slowly holding the wings folded against the body, and the bird was picked up with a towel because "Birds of prey" 
have sharp talons used for catching. In this current case the kite showed some symptoms like head tilting and periods of eye closing which indicated severe illness or trauma. Feathers fluffed out could mean the bird was unwell and tried to warm itself. Immobilization or fixation of cervical dislocation was done by Coaptation splint with X-ray film by preventing displacement or angulation of cervical vertebrae, movement and pain (Kumar Amresh, 2000). Fractured shoulder extremity of left coracoid was managed by use of figure of 8 bandage with body wrap bandage using soft padding material. Howard and Redig (1993) reported successful management of 36 percent for birds with closed fractures and 15 percent with compound fractures in wild raptors with same kind of fracture management with external coaptation and/or bandaging techniques. More complex fractures were fixed surgically, with techniques described by Calvo Carrasco (2019) and Ponder and Redig (2016). The use of external coaptation without surgical repair has been associated with poorer outcomes (Ponder and Redig, 2016); but

\section{REFERENCES}

Calvo Carrasco D, 2019. Fracture management in avian species. Vet Clin North Am Exot Anim Pract, 22: 223-238, doi: 10.1016/j.cvex.2019.02.002

Ceulemans S, Guzman D, Olsen G, Beaufrère H and PaulMurphy J, 2014. Evaluation of thermal antinociceptive effects after intramuscular administration of buprenorphine hydrochloride to American kestrels (Falco sparverius). Am J Vet Res, 75(8): 705-710, doi: 10.2460/ajvr.75.8.705

Fowler ME, 2001. Order Stringiformes (Owls): Biol, Med and Surg, Iowa Univ Press, pp 1-536

Howard DJ and Redig PT, 1993. Analysis of Avian Fracture Repairs: Implications for Captive and Wild Birds. In Proceedings of the Annual Conference of the Association of Avian Veterinarians. Florida: Association of Avian Veterinarians, pp 78-83 it is helpful in settings with lower budgets and without surgical intervention. Even application of tape splints provides good outcome in birds (Wright et al., 2018). Regarding post rescue management the bird was kept in a quiet place under quarantine in a towel padded cage so that the bird would not be disturbed and injured. The bird was monitored after every two hours for proper observation of the patient. During this period the bird was unable to hold its head up, so oral fluid administration was not done to avoid asphyxia and subcutaneous fluid administration was carried out (Mullineaux and Keeble, 2016). The present case of the kite was effectively treated to recover from wing wounds and cervical dislocation successfully by proper fluid management, antibiotic therapy, anti inflammatory therapy and proper nourishment with applicable surgical intervention.

An injured kite with wing wounds and cervical dislocation was treated successfully.

Conflict of interest: Authors have no conflict of interest in this study.

Kumar Amresh, 2000. Veterinary Surgical Techniques. $2^{\text {nd }}$ edn., Vikas Pub House Pvt. Ltd, New Delhi, pp 193-194

Mullineaux E and Keeble E, 2016. First aid and emergency care. In E. Mullineaux, and E. Keeble, BSAVA Manual of Wildlife Casualties, $2^{\text {nd }}$ edn., Gloucester: British Small Anim Vet Assoc, pp 37-55

Ponder JB and Redig P, 2016. Orthopaedics. In B. L. Speer, Current Therapy in Avian Medicine and Surgery. Missouri, Elsevier, pp 657-668

Wright L, Mans C, Olsen G, Doss G, Amene EW et al., 2018. Retrospective evaluation of tibiotarsal fractures treated with tape splints in birds: 86 cases (2006-2015). J Avian Med Surg, 32(3): 205-209, doi: 10.1647/20162241

Received 09.01.2021, Accepted - 21.04.2021, Published - 01.06.2021

Section Editor: Prof. S. K. Nandi, Associate Editor 